2020-12-15

\title{
Compact floating wave energy converter arrays: Mooring loads and survivability through scale physical modelling
}

\section{Gomes, RPF}

http://hdl.handle.net/10026.1/16435

10.1016/j.apenergy.2020.115982

Applied Energy

Elsevier

All content in PEARL is protected by copyright law. Author manuscripts are made available in accordance with publisher policies. Please cite only the published version using the details provided on the item record or document. In the absence of an open licence (e.g. Creative Commons), permissions for further reuse of content should be sought from the publisher or author. 


\title{
Compact floating wave energy converters arrays: Mooring loads and survivability through scale physical modelling
}

Rui P. F. Gomes*a, Luís M. C. Gato ${ }^{\text {, }}$, João C. C. Henriques ${ }^{a}$, Juan C. C. Portillo $^{\mathrm{a}}$, Ben D. Howey ${ }^{\mathrm{b}}$, Keri M. Collins ${ }^{\mathrm{b}}$, Martyn R. Hann ${ }^{\mathrm{b}}$, Deborah M. Greaves $^{\mathrm{b}}$

${ }^{a} I D M E C$, Instituto Superior Técnico, Universidade de Lisboa, Av. Rovisco Pais 1, 1049-001 Lisboa, Portugal

${ }^{b}$ School of Engineering, Computing and Mathematics, University of Plymouth, Drake Circus, Plymouth PL4 8AA, UK

\begin{abstract}
The current cost of electricity has been preventing the technological progress of wave energy converters. The use of compact wave energy converters arrays is seen as a technological breakthrough for reducing these costs. These array configurations aim to maximize the energy extracted per unit area of marine space and to promote the sharing of components and installation, operation and maintenance tasks. Mooring lines are fundamental components in these systems and represent a considerable portion of the project cost. Reducing the number of mooring lines through the application of arrays with interbody connections has a high potential for cost reduction. In this paper, we present the experimental study of different configurations of a five-device array of spar-buoy oscillating-water-column wave energy converters in a wave basin, focusing on the analysis of the devices motion and the mooring line loads. The study compares the performance of a single isolated device, an array with independently-moored devices and three arrays with inter-body connections, with different levels of connectivity in the mooring arrangement. Tests were carried out for moderate and extreme wave conditions. Results show good performance for all configurations when subjected to moderate sea conditions. Under extreme sea conditions, high peak tensions were ob-
\end{abstract}

\footnotetext{
${ }^{*}$ Corresponding author

Email address: ruigomes@tecnico.ulisboa.pt (Rui P. F. Gomes*)
} 
served in the lines of all array configurations. Particularly large values were detected in the inter-body lines, caused by their full extension. Based on these results, guidelines for the design of mooring systems for compact wave energy converter arrays are presented.

Keywords: Wave energy conversion, compact array, physical model testing, mooring loads, inter-body mooring connection, spar-buoy oscillating water column

\section{Introduction}

Wave energy conversion technologies for the generation of electricity have been under research since the 1970s, with hundreds of developed concepts [1]. So far, no technology has yet reached a commercial level. The high cost of electricity when compared with other renewable energy technologies has been identified as the main obstacle [2]. One course of action to develop wave energy technology is its application with other technologies to take advantages of possible synergies [3]. The direct integration of wave energy converters (WECs) in floating wind platforms has shown a prospect for cost reduction and for the improvement of the system survivability [4]. The application of WECs in large floating platforms used to create space in the sea for various purposes (airports, seaports, aquaculture, recreation, residential, etc.) is seen as greatly beneficial [5]. Despite these possibilities, the deployment of compact WEC arrays with the unique purpose of electrical generation, resulting in an increase of energy extraction per unit seabed area, still has the potential to provide a significant cost reduction with the additional advantage of reducing environmental impacts [6]. This cost reduction is obtained through the sharing of system components (mooring lines, anchors, etc.), power cables, as well as through the sharing of installation, operation and maintenance activities.

Floating point absorbers, a class of WECs in which the horizontal dimensions are much smaller than the incident wavelength, typically have a power capacity of few hundred $\mathrm{kW}$ per device [7]. In order to reach the capacity of the actual largest offshore wind farms (300-700 MW) [8], WECs should be deployed in dense arrays with hundreds of devices. The selection of the array spacing and layout is crucial for converting energy in an efficient manner [9]. Constructive hydrodynamic effects are known to significantly enhance the overall power extraction per converter when compared with an isolated de- 
vice [10]. The design of arrays requires models that are capable of assessing the wave-body interactions within the array [11] and incorporate the power take-off control of individual devices [12], which is deeply linked with the device hydrodynamics. Recent works have shown that the complexity and computational effort of hydrodynamic models can be significantly reduced through the use of surrogate models to facilitate the application of control strategies [13]. In addition to maximizing power performance, array design methods should take into account the minimization of occupied space and the access for maintenance operations [14].

Floating WECs require a mooring system to be kept on station. The spread mooring system is commonly used, consisting of several independent lines connecting the WEC to anchors installed on the seabed. This type of mooring system typically represents $20-30 \%$ of the WEC structural cost $[15,16]$. For this reason, the decrease of the total line length and number of anchors is seen by the industry as having a major potential for the reduction of costs over the project lifetime [17, 18]. Initial developments of shared moorings systems were carried out by the ocean aquaculture industry to enhance production without significantly increasing the covered area [19]. The application in WECs was also considered by sharing anchors and using lines between adjacent devices [20, 21]. Numerical simulations of a WEC array with inter-body connections have shown the potential of enhancing power conversion performance when compared with an equivalent array with independently moored devices, for single-body WECs reacting against the seabed [21] and for two-body floating WECs [22]. However, shared mooring lines add complexity to the design of such systems due to the coupled dynamics of adjacent devices [20]. To date, no significant work has been dedicated to the design of such systems. Due to the complexity of the system, experimental tests are still the most practical method to obtain reliable results, even though some limitations exist and the costs are relatively high [23]. Most experimental studies of WEC arrays concern mainly devices reacting against a fixed reference (i.e. without requiring a mooring system) [24], devices attached to a single floating structure (i.e. requiring a single mooring system) [25] or floating independently-moored devices [26]. In these studies, major focus is given to the power performance [27] and to the wave field generated by the presence of the array [28]. An experimental study on a three-device array of floating WECs with inter-body mooring connections can be found in Ref. [29], based on the mooring configuration presented in Ref. [21]. The analysis was focussed on the device performance and on the 
mooring loads, using the same bottom-moored lines as the isolated device used as a reference. When compared with the isolated device, slightly larger mooring loads were observed for the array. However, it was not possible to assess if the differences were related to the hydrodynamic array effects or to the inter-body mooring configuration. The work published until now still did not clarify how can the hydrodynamic effects affect the mooring system response. In this work, we investigate this gap of knowledge by considering a larger array (five devices) with inter-body mooring connections. Additionally, we analyse the effect that different levels of line connectivity have on the system performance. The device motion and line load performance are compared with an isolated device and an array of independently-moored devices, which will provide a baseline comparison that also includes the array hydrodynamic effect.

Due to the wide application of mooring systems, namely in the offshore oil and gas industry, several guidelines and standards for mooring design are available $[30,31]$. In general, the design criteria are based on three states: withstand failure under extreme sea conditions, maintain system integrity with a limited amount of failures, and account for material fatigue due to cyclic loading. Unlike other ocean utilization purposes, floating WECs require, in general, high motion amplitude in specific modes at commonly occurring wave periods. Besides providing stationkeeping, the mooring system has to allow displacement and rotations in specific modes, which requires particular and more complex designs [32]. In heaving WECs, a common solution to this issue consists on the use of a slack-line configuration, comprising a line with a clump weight and a float [33]. Experimental results showed that this configuration has a low dynamic tension and a good performance in extreme sea states [34]. Applications of this mooring configuration in a sparbuoy oscillating-water-column (OWC) device are available in the literature, for a two-line mooring system [35] and for a three-line mooring system [29]. Numerical simulations of the latter case are presented in Ref. [36]. In this work, we apply this slack-line configuration for the bottom mooring lines. As an additional advantage, this type of line helps the design of the interbody connected array mooring system, as it allows the adjustment of the line components for achieving a required specification (pre-tension, stiffness).

The design of WECs requires the simulation of extreme sea conditions to analyse the device and its mooring system response. Available options consist of simulating irregular-wave sea states characterising the most stormy conditions of a given site, or a single wave (focused wave) representing the 
worst-case scenario [37]. Such analysis can be done numerically, by applying high-fidelity models [38] capable of accounting for the mooring line dynamics $[39,40]$, or experimentally in a wave tank [41, 42]. Despite limitations, such as scale effects [43], experimental tests are still the best option to obtain sound results $[44,45]$.

This paper studies the mooring loads of a compact five-device array of spar-buoy OWC WECs. The spar-buoy OWC consists of an axisymmetric floating structure with an inner non-uniform cross-section OWC tube open at the bottom to the sea water and connected at the top to an air chamber [46]. The motions of the OWC inner free surface and of the floating structure in waves produce alternate variations of the air chamber volume, forcing air through a turbine that drives an electrical generator. This study presents experimental results of the mooring loads for three arrays with independentlymoored devices, and compare them with the mooring loads from an isolated device and from an array with independently-moored devices. The devices' response to moderate and extreme sea conditions is considered. With these results, we aim to characterize the motions and mooring loads from the different array configurations. By testing an isolated device and an independently moored array, we distinguish the contributions from hydrodynamic effects and from the different mooring configurations. Ultimately, we intend to understand the limitations and the potential of the use of inter-body connections in WEC arrays. Experimental studies of WEC arrays with inter-body mooring connections are still very scarce in the literature despite the enormous potential benefits of the concept. This work aims to increase the understanding of this issue. Section 2 presents the different array configurations considered in this work and a description of their design. The experimental setup is described in Section 3. Results obtained for each array configuration are presented and discussed in Section 4. Relevant conclusions on this work are detailed in Section 5.

\section{Array configurations}

In this work, we study the response of four different five-device arrays with the same arrangement and separating distance yet with distinct levels of mooring line connectivity. The five-device array is organized in a die-type configuration, with four devices positioned in the vertex of a square (named here as corner devices) and a device in the centre of the virtual square (named here as central device). The spar-buoy OWC device is used in this study. 


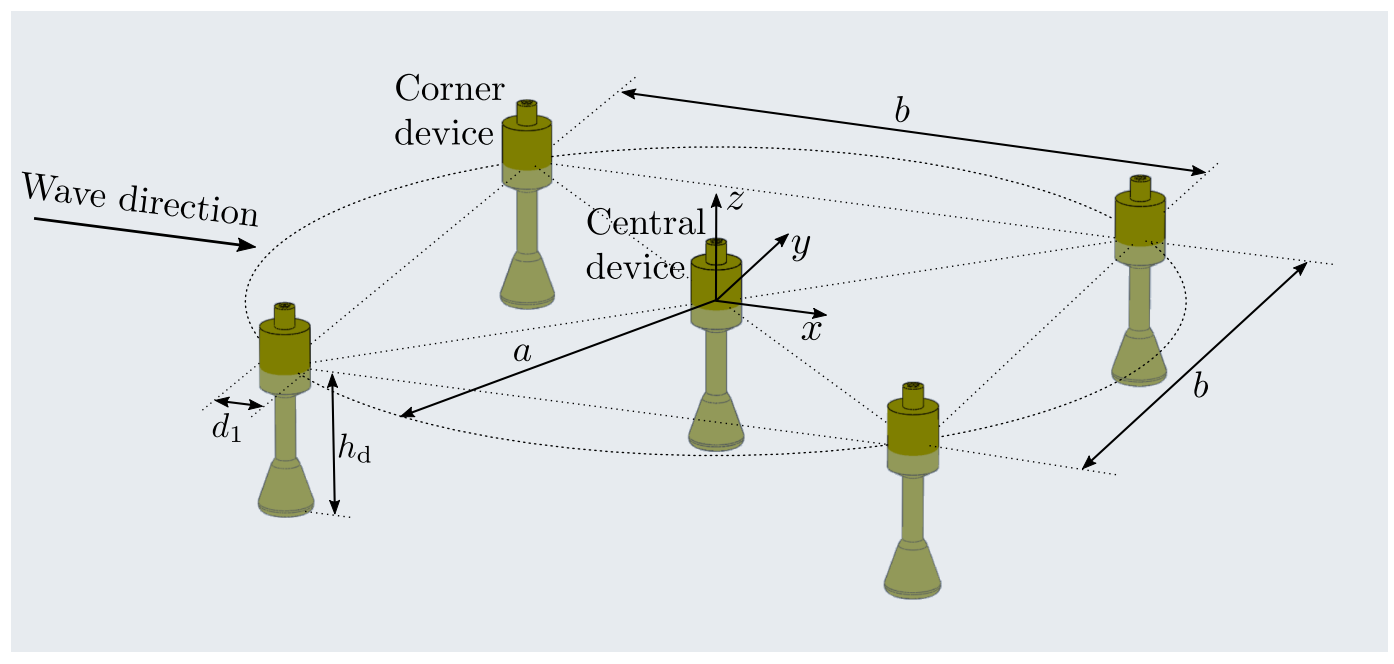

Figure 1: Three-dimensional view of the five-device die-type array of spar-buoy OWC WECs. The buoy diameter is $d_{1}=12 \mathrm{~m}$ and the buoy draft is $h_{\mathrm{d}}=36 \mathrm{~m}$. The separating distances of the array are $a=112.8 \mathrm{~m}$ and $b=159.5 \mathrm{~m}$.

Table 1: Physical characteristics of the studied spar-buoy OWC devices. Values refer to full scale. The symbol $\sigma^{*}$ represents the root-mean-square value of the corresponding parameter considering measurements of the five models, normalized by the design value of the parameter.

\begin{tabular}{lrr}
\hline Parameter & Value & $\sigma^{*}[\%]$ \\
\hline Buoy diameter, $d_{1}[\mathrm{~m}]$ & 12 & 1.2 \\
OWC diameter, $d_{2}[\mathrm{~m}]$ & 4.82 & \\
Draft, $h_{\mathrm{d}}[\mathrm{m}]$ & 35.99 & \\
Total length $[\mathrm{m}]$ & 50.99 & 0.1 \\
Metacentric height, $\overline{G M}[\mathrm{~m}]$ & 2.08 & 14.4 \\
Buoy mass, $m_{\mathrm{b}}[\mathrm{kg}]$ & $1.217 \times 10^{6}$ & 1.3 \\
Moment of inertia, $I_{x x}\left[\mathrm{~kg} \mathrm{~m}^{2}\right]$ & $0.325 \times 10^{9}$ & \\
Moment of inertia, $I_{z z}\left[\mathrm{~kg} \mathrm{~m}^{2}\right]$ & $0.029 \times 10^{9}$ & \\
\hline
\end{tabular}

Fig. 1 presents a three-dimensional view of the spar-buoy OWC five-device array. The separating distance $a$ between the central and the corner devices is $112.8 \mathrm{~m}$ and the water depth is $80 \mathrm{~m}$.

The spar-buoy OWC device geometry is based on the optimized version presented in [47], for a buoy with a diameter $d_{1}=12 \mathrm{~m}$ and a draft $h_{\mathrm{d}}=36 \mathrm{~m}$. Table 1 presents relevant physical properties of the device at full scale. These 

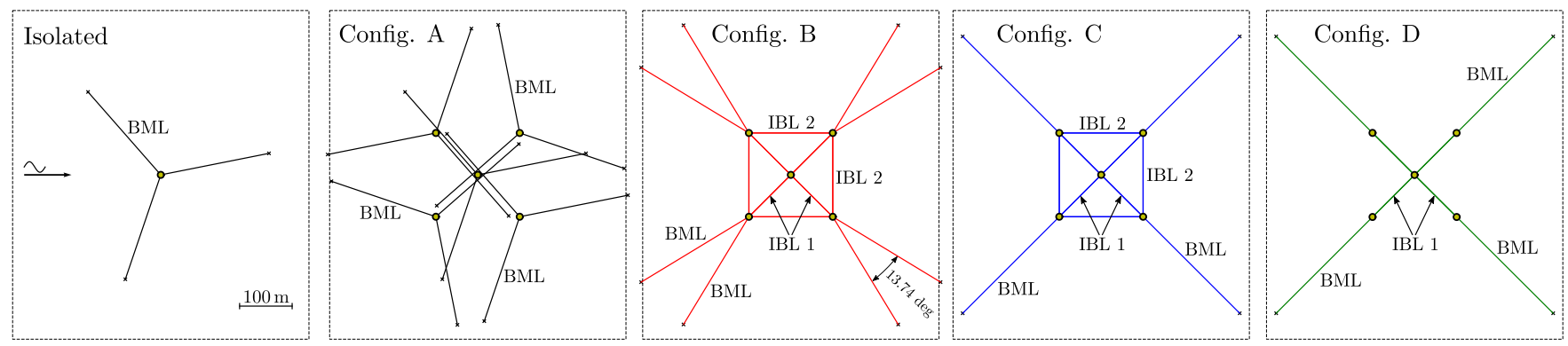

Figure 2: Schematic representation of the mooring line arrangement of the isolated device and of the four array configurations (A, B, C, D). The points represent the position of the devices, the crosses indicate the location of the anchors. The bottom mooring lines (BML) and inter-body mooring lines (IBL1 and IBL2) are indicated. The dashed box represent the working area in the wave basin, where it is possible to deploy the anchors. The wavemakers are to the left of the configurations and the absorption beach is to the right.

Table 2: Characteristics of the mooring system components, lengths and positions, for array configuration A.

\begin{tabular}{lr}
\hline Parameter & BML \\
\hline Pre-tension, $f_{0}[\mathrm{kN}]$ & 1047 \\
Fairlead angle, $\alpha_{\mathrm{f}}[\mathrm{deg}]$ & -75.8 \\
Total line length, $l_{\mathrm{t}}[\mathrm{m}]$ & 246.68 \\
Clump mass ratio, $m_{\mathrm{cw}} / m_{\mathrm{b}}[-]$ & $106.0 \times 10^{-3}$ \\
Clump weight position, $s / l_{\mathrm{t}}[-]$ & 0.209 \\
Floater mass ratio, $m_{\mathrm{f}} / m_{\mathrm{b}}[-]$ & $0.27 \times 10^{-3}$ \\
Floater position, $s / l_{\mathrm{t}}[-]$ & $0.283, \ldots, 0.312$ \\
Chain length ratio, $l_{\mathrm{c}} / l_{\mathrm{t}}[-]$ & 0.187 \\
Total length ratio, $l_{\mathrm{t}} / l_{\mathrm{e}}[-]$ & 1.126 \\
\hline
\end{tabular}

include the diameter of the buoy $d_{1}$ and diameter of the OWC $d_{2}$, the mass of the buoy $m_{\mathrm{b}}$, and the moments of inertia measured about axes parallel to the $x$ - and $z$-axis and passing through the centre of mass.

The five different configurations tested are presented in Fig. 2, showing the mooring line arrangements of the isolated device and of each array configuration (A, B, C, D). The isolated device is used as a reference. This device is moored to the sea bottom with three bottom mooring lines. In configuration $\mathrm{A}$, the devices in the array are independently moored, each one with three bottom mooring lines, as in the isolated device. Configurations B, 


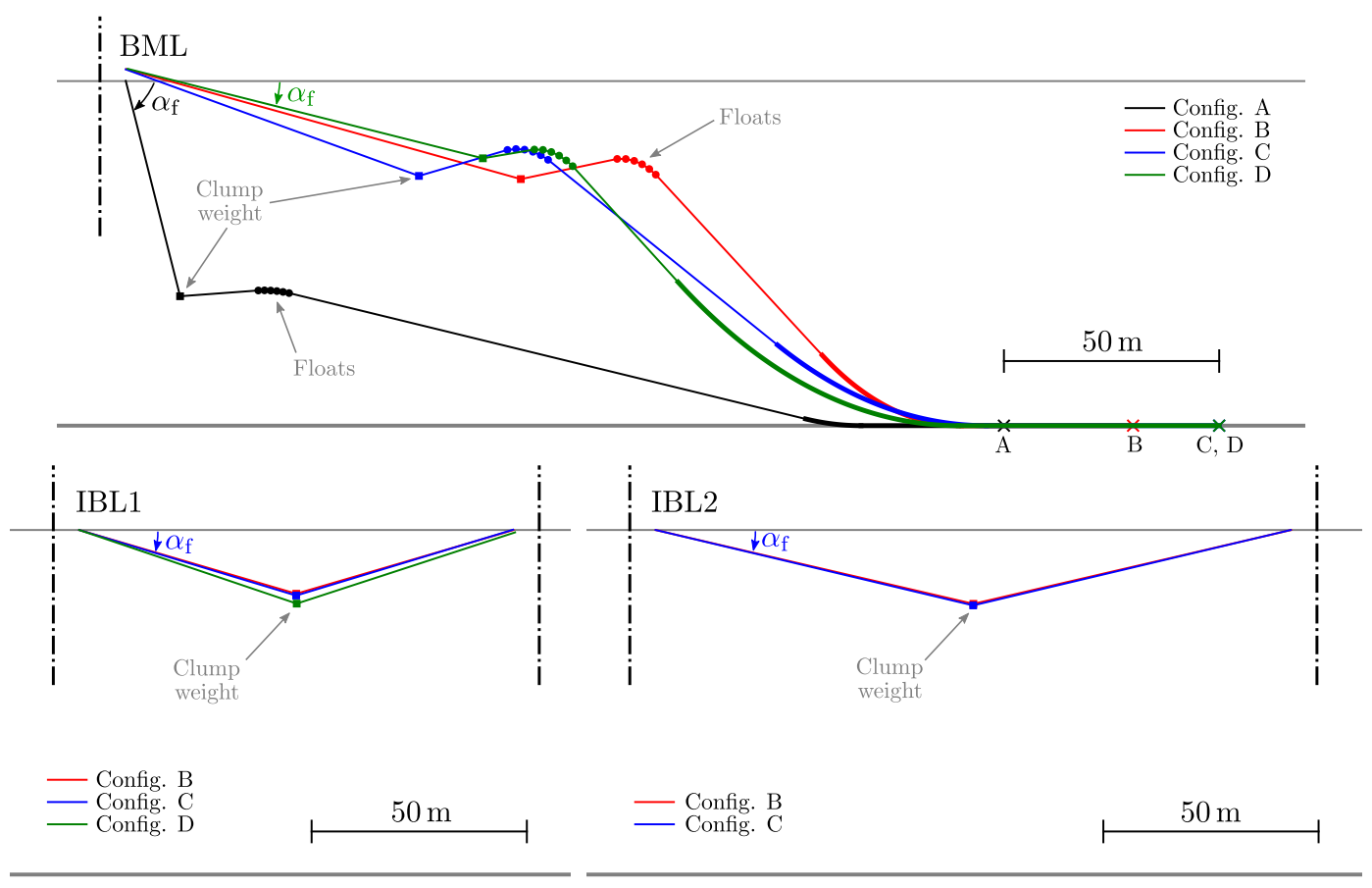

Figure 3: Schematic representation of the bottom mooring lines (BML) and inter-body mooring lines (IBL1 and IBL2), for all configurations. The thinner lines represent the rope, the thicker lines represent the chain section, the square indicate the position of the clump weight and the circles show the location of the floats.

Table 3: Characteristics of the mooring system components, lengths and positions, for array configuration B.

\begin{tabular}{lrrr}
\hline Parameter & BML & IBL 1 & IBL 2 \\
\hline Pre-tension, $f_{0}[\mathrm{kN}]$ & 379 & 420 & 220 \\
Fairlead angle, $\alpha_{\mathrm{f}}[\mathrm{deg}]$ & -15.6 & -16.4 & -13.1 \\
Total line length, $l_{\mathrm{t}}[\mathrm{m}]$ & 262.28 & 105.12 & 151.52 \\
Clump mass ratio, $m_{\mathrm{cw}} / m_{\mathrm{b}}[-]$ & $18.2 \times 10^{-3}$ & $24.3 \times 10^{-3}$ & $10.2 \times 10^{-3}$ \\
Clump weight position, $s / l_{\mathrm{t}}[-]$ & 0.363 & 0.500 & 0.500 \\
Floater mass ratio, $m_{\mathrm{fl}} / m_{\mathrm{b}}[-]$ & $1.12 \times 10^{-3}$ & & \\
Floater position, $s / l_{\mathrm{t}}[-]$ & $0.450, \ldots, 0.488$ & & \\
Chain length ratio, $l_{\mathrm{c}} / l_{\mathrm{t}}[-]$ & 0.294 & & \\
Total length ratio, $l_{\mathrm{t}} / l_{\mathrm{e}}[-]$ & 1.057 & 1.043 & 1.027 \\
\hline
\end{tabular}

$\mathrm{C}$ and D refer to arrangements with inter-body and bottom slack-mooring connections. Each of those configurations present different number of lines. 
Table 4: Characteristics of the mooring system components, lengths and positions, for array configuration $\mathrm{C}$.

\begin{tabular}{lrrr}
\hline Parameter & BML & IBL 1 & IBL 2 \\
\hline Pre-tension, $f_{0}[\mathrm{kN}]$ & 739 & 405 & 223 \\
Fairlead angle, $\alpha_{\mathrm{f}}[\mathrm{deg}]$ & -20.0 & -16.9 & -13.4 \\
Total line length, $l_{\mathrm{t}}[\mathrm{m}]$ & 279.48 & 105.28 & 151.60 \\
Clump mass ratio, $m_{\mathrm{cw}} / m_{\mathrm{b}}[-]$ & $46.7 \times 10^{-3}$ & $24.1 \times 10^{-3}$ & $10.6 \times 10^{-3}$ \\
Clump weight position, $s / l_{\mathrm{t}}[-]$ & 0.259 & 0.500 & 0.500 \\
Floater mass ratio, $m_{\mathrm{fl}} / m_{\mathrm{b}}[-]$ & $1.83 \times 10^{-3}$ & & \\
Floater position, $s / l_{\mathrm{t}}[-]$ & $0.336, \ldots, 0.372$ & & \\
Chain length ratio, $l_{\mathrm{c}} / l_{\mathrm{t}}[-]$ & 0.383 & & \\
Total length ratio, $l_{\mathrm{t}} / l_{\mathrm{e}}[-]$ & 1.046 & 1.045 & 1.028 \\
\hline
\end{tabular}

Table 5: Characteristics of the mooring system components, lengths and positions, for array configuration D.

\begin{tabular}{lrr}
\hline Parameter & BML & IBL 1 \\
\hline Pre-tension, $f_{0}[\mathrm{kN}]$ & 768 & 752 \\
Fairlead angle, $\alpha_{\mathrm{f}}[\mathrm{deg}]$ & -14.3 & -18.3 \\
Total line length, $l_{\mathrm{t}}[\mathrm{m}]$ & 279.52 & 106.72 \\
Clump mass ratio, $m_{\mathrm{cw}} / m_{\mathrm{b}}[-]$ & $31.3 \times 10^{-3}$ & $49.3 \times 10^{-3}$ \\
Clump weight position, $s / l_{\mathrm{t}}[-]$ & 0.304 & 0.500 \\
Floater mass ratio, $m_{\mathrm{fl}} / m_{\mathrm{b}}[-]$ & $2.20 \times 10^{-3}$ & \\
Floater position, $s / l_{\mathrm{t}}[-]$ & $0.348, \ldots, 0.384$ & \\
Chain length ratio, $l_{\mathrm{c}} / l_{\mathrm{t}}[-]$ & 0.486 & \\
Total length ratio, $l_{\mathrm{t}} / l_{\mathrm{e}}[-]$ & 1.048 & 1.059 \\
\hline
\end{tabular}

Table 6: Overall characteristics of the mooring system components for all array configurations. For each parameter, the relative value with respect to configuration A is presented. The component mass refers to the sum of masses of all clump weights and floats used in the array.

\begin{tabular}{lrrrrrrr}
\hline Config. & Number & \multicolumn{2}{r}{ Line length } & \multicolumn{2}{r}{ Chain length } & \multicolumn{2}{r}{ Component mass } \\
& of lines & {$[\mathrm{m}]$} & {$[\%]$} & {$[\mathrm{m}]$} & {$[\%]$} & {$[\mathrm{kg}]$} & {$[\%]$} \\
\hline A & 15 & 3700 & 100 & 692 & 100 & $1.965 \times 10^{6}$ & 100 \\
$\mathrm{~B}$ & 16 & 3125 & 84 & 617 & 89 & $0.411 \times 10^{6}$ & 21 \\
$\mathrm{C}$ & 12 & 2145 & 58 & 428 & 62 & $0.450 \times 10^{6}$ & 23 \\
$\mathrm{D}$ & 8 & 1545 & 42 & 543 & 79 & $0.457 \times 10^{6}$ & 23 \\
\hline
\end{tabular}


The bottom mooring lines (BMLs) consists of a chain segment connected to an anchor and lying on the sea floor, which is attached to a synthetic rope segment with six floats (in a 'lazy-S' type arrangement) and a clump weight fixed along the rope. On the other end, the rope is connected to the device's fairlead, which corresponds to the point were the line attaches the device. The inter-body mooring line (IBL) consists of a rope connected on both ends to two different devices. There are two distinct arrangements for this type of line, depending if it is connecting the central to a corner device (denominated IBL1), or if it is connecting two neighbouring corner devices (denominated IBL2). A clump weight, that provides a pre-tension, is located in the middle of this rope. Fig. 3 shows the two types of lines considered. The chain segment consists of a stud link chain with a diameter of $237 \mathrm{~mm}$, corresponding to submerged weight per unit length of $10.55 \mathrm{kN} / \mathrm{m}$ and an axial stiffness per unit length of $5055 \mathrm{MN}$. The synthetic ropes have a diameter of $65 \mathrm{~mm}$, with a spiral strand construction. The rope has a submerged weight per unit length of $20.4 \mathrm{~N} / \mathrm{m}$ and an axial stiffness per unit length of $49.8 \mathrm{MN}$. The density of the clump weights and floats are $5600 \mathrm{~kg} / \mathrm{m}^{3}$ and $150 \mathrm{~kg} / \mathrm{m}^{3}$, respectively. The sea water density considered for the full-scale application is $\rho=1025 \mathrm{~kg} / \mathrm{m}^{3}$.

The mooring lines of the arrays with inter-body connections were specifically designed in order to match the stiffness of the isolated device in the wave propagation direction (surge). The BMLs of array configuration A were based on the lines presented in Ref. [48], for an isolated device. The original line length was reduced to fit all anchors inside the working area of the wave basin (564 $\mathrm{m}$ long and $626 \mathrm{~m}$ wide at full scale), and the lines were rotated relative to the device vertical axis to avoid collision of lines during operation. The isolated device has the same mooring arrangement as the central device of configuration $\mathrm{A}$. In the configurations with inter-body connections, the corner devices have connections to the bottom (B,C,D), connections to other exterior devices $(B, C)$ and a connection to the interior device $(B, C, D)$. For configurations B, C and D, only the stiffness of the exterior devices was targeted to be the same value as the isolated device. The distances between devices were kept unchanged.

The design was carried out using a quasi-static mooring line model considering inelastic and weightless lines, and an inelastic catenary at the bottom for the BMLs. The model was developed in-house and its description can be found in [36]. This model was applied to determine the mooring line tensions and angles at the fairlead when a device was subjected to a specific 
displacement, therefore evaluating the mooring stiffness. In the particular case of the arrays with inter-body connections, the forced displacement of a device also introduced displacements in the interconnected devices, which required a momentum balance in all devices. The optimization algorithm COBYLA was applied to facilitate the design process $[49,50]$. This algorithm performs linear approximations to the objective and constraint functions through the interpolation at the vertices of a simplex with $n+1$ points, where $n$ is the number of optimization variables. Mooring design had the objective of minimizing the difference between the specified surge stiffness and the one determined by the model, while guaranteeing a force balance in all devices for the still water condition. Several constraints were adopted for the BML, considering all displacements, namely: $(i)$ the minimum position of the clump weight was at $z=-65 \mathrm{~m}$; $(i i)$ the maximum position of the clump weight was at $z=-5 \mathrm{~m}$; (iii) the maximum position of the floats was at $z=-10 \mathrm{~m} ;(i v)$ the minimum horizontal distance between the fairlead and the clump weight was set to $5 \mathrm{~m} ;(v)$ the minimum horizontal distance between the clump weight and the floats was set to $5 \mathrm{~m}$; (vi) the minimum length of chain lying in the bottom was set to $15 \mathrm{~m}$. As a result, each configuration had its own line lengths, float mass and clump weight mass. For the application of the design constraints, displacements between $-15 \mathrm{~m}$ and $15 \mathrm{~m}$ in the $x$-axis direction were considered. The surge stiffness was determined through linear regression of the force on the $x$-axis direction due to the displacements of the device at $x=-2.5,0,2.5 \mathrm{~m}$. The specified surge stiffness was set to $35.5 \mathrm{kN} / \mathrm{m}$. Tables $2,3,4$ and 5 show the relevant characteristics of the mooring system, for array configurations A, B, C and D, respectively. The parameter $f_{0}$ is the line pre-tension measured at the fairlead, $\alpha_{\mathrm{f}}$ is the angle of the line with the horizontal plane at the fairlead, $l_{\mathrm{t}}$ is the total length of the mooring line (including rope and chain segments), $l_{\mathrm{c}}$ is the length of the chain segment, $l_{\mathrm{e}}$ is the distance between the two ends of a given line (the end of the line can either be a fairlead of an anchor, depending on whether the line is connected between devices or to the bottom), $m_{\mathrm{cw}}$ is the mass of the clump weight, and $m_{\mathrm{f}}$ is the mass of a single float.

Table 6 shows the relevant total quantities of the array, as the number of lines, the total line length, the chain length and the total mass of the mooring components, which includes the clump weights and floats. The relative value of the quantity relative to the corresponding value of configuration $\mathrm{A}$ is also presented. When compared with configuration A, configurations $\mathrm{C}$ and D present significantly smaller values in the number of lines, line length, 
chain length and component mass. The reduction of the amount of material indicates that these configurations have the potential to decrease the cost of the system. In the case of configuration B, the differences with $\mathrm{A}$ are not so significant, mainly due to requiring two BML per corner device, instead of one as in $\mathrm{C}$ and $\mathrm{D}$.

It is worth noticing that the case studied here considers a moderate water depth ( $80 \mathrm{~m}$ at full scale). For larger water depths, the reductions in line length are expected to be significantly higher.

\section{Experimental setup}

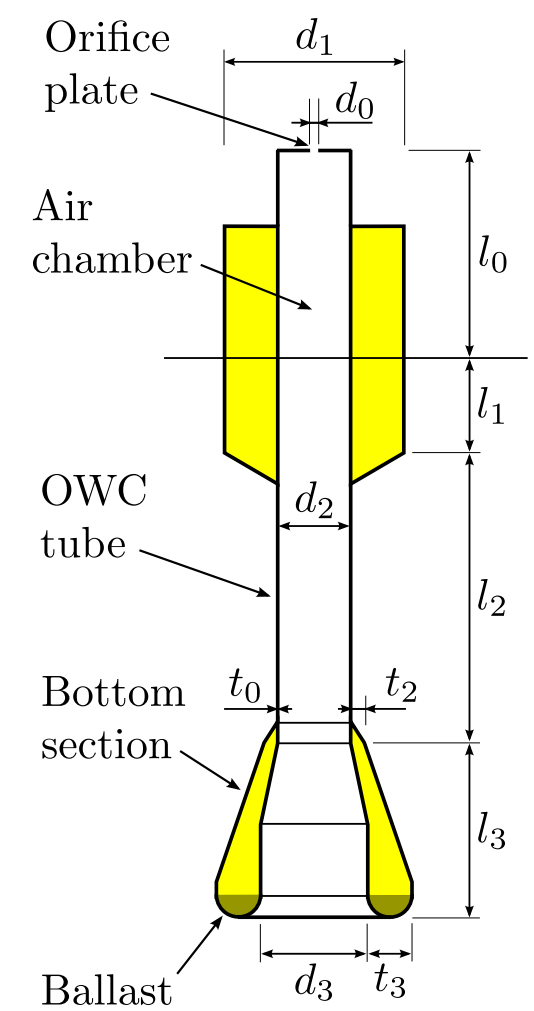

Figure 4: Cut-section view of the spar-buoy OWC model with identification of relevant dimensions. The dimensions of the device at model scale $(1: 40)$ are: $d_{1}=0.300 \mathrm{~m} ; d_{2}=$ $0.125 \mathrm{~m} ; d_{3}=0.180 \mathrm{~m} ; t_{0}=0.003 \mathrm{~m} ; t_{2}=0.024 \mathrm{~m} ; t_{3}=0.075 \mathrm{~m} ; l_{0}=0.375 \mathrm{~m} ; l_{1}=$ $0.125 \mathrm{~m} ; l_{2}=0.489 \mathrm{~m} ; l_{3}=0.286 \mathrm{~m}$. 


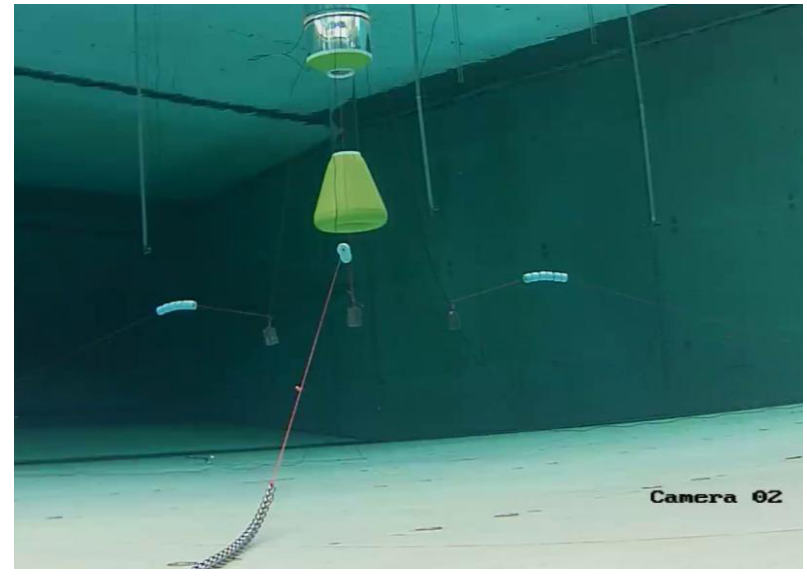

Figure 5: Underwater view of the mooring arrangement of the isolated device setup.

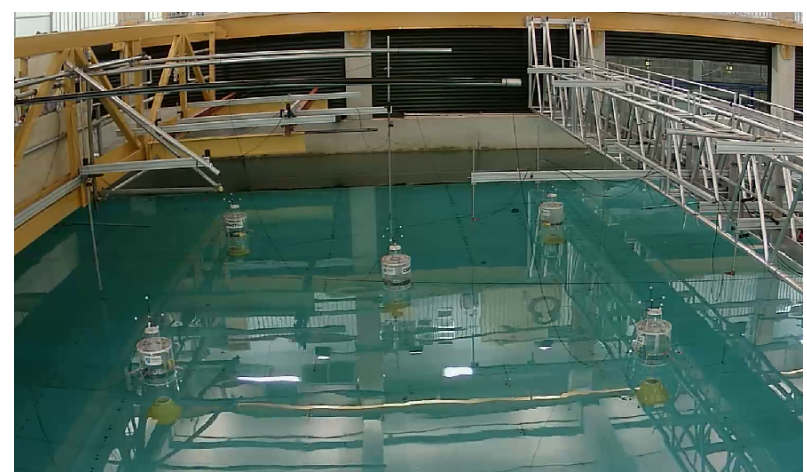

Figure 6: View of the five-device array with mooring configuration C.

The experimental tests of the isolated and five-device array configurations of the spar-buoy OWC 1:40 th-scaled model were carried out at the large ocean basin of the COAST (Coastal, Ocean And Sediment Transport) Laboratory, University of Plymouth (UK). The wave generation system, developed by Edinburgh Designs Ltd, consists of 24 flap-type paddles hinged at depth of $2 \mathrm{~m}$. The wave basin is $35 \mathrm{~m}$ long, $15.5 \mathrm{~m}$ wide and has a section with a variable-depth floor. In these experiments, the water depth was set to $2 \mathrm{~m}$ to simulate the water depth $(80 \mathrm{~m})$ of the deployment site off the coast of Leixões, Portugal.

The model of the spar-buoy OWC was based on the geometry and properties presented in Table 1 and in Fig. 4. The length scale of the tests (1:40) was established by combining the following factors: $(i)$ limitation on the 
basin dimensions to accommodated the scaled mooring lines and corresponding anchors; (ii) minimization line length and mooring scope via an adequate mooring design; ( iii) simulation of a water depth considerably larger than the spar-buoy OWC draft. Experiments and model were scaled using Froude scaling criterion [51]. The density of the water in the basin was $\rho=1000 \mathrm{~kg} / \mathrm{m}^{3}$. Since the water density is different from the sea-water value $\left(\rho=1025 \mathrm{~kg} / \mathrm{m}^{3}\right)$, moments of inertia and mass of the model were determined taking into account the model-to-prototype-water-density ratio. The model was produced from a combination of aluminium and acrylic. The upper part of the model was made of acrylic to allow the visualization of the inner free surface displacement. The bottom section of the buoy (see Fig. 4) was built in aluminium, which consists of conical, cylindrical and toroidal surfaces. The OWC tube and the upper floating section were made of acrylic, except for the conical surface near the free surface, which is also aluminium. An orifice plate was applied at the top of the OWC chamber to simulate the turbine damping effect. The orifice-plate-to-OWC-surface-area ratio was set to 0.0215 , a value selected from previous experiments with an isolated sparbuoy OWC device [52], which showed a good power extraction performance. For the experiments at the 1:40 scale, the chain section was simulated using a $4 \mathrm{~mm}$ stainless steel (316) short link chain. For the synthetic rope, a $1.6 \mathrm{~mm}$ diameter UHMWPE (ultra-high molecular weight polyethylene) line was applied (LIROS DC Dyneema SK78 Competition Kite Line). The clump weights were build in a cylindrical shape with a diameter of $60 \mathrm{~mm}$ and the length was adjusted to match the properties specified in Tables 2, 3, 4 and 5 . The floats were made from cylindrical polystyrene parts (with $50 \mathrm{~mm}$ diameter) and were attached along the line. The mooring lines were attached to the buoy near the free surface through a hose-clip. Fig. 5 shows a view of the mooring lines of the isolated device setup. Three mooring lines, with the respective clump weight and floats, are displayed. The chain section lying in the bottom is also visible.

Twin-wire resistive wave gauges were used to measure the water elevation $(\eta)$ at different positions in the wave basin. The incident wave conditions were measured using a wave gauge positioned in the centre of the array by performing tests without the models installed. Through this procedure, the effect of radiated and diffracted waves was removed. We also found that the wave gauge located at the longitudinal position of the central device, near the basin side wall, provided very similar results to the ones captured by the wave gauge used without the models, and therefore could be used as a proxy. 
The wave gauges were calibrated on a daily basis. Typically, the calibration error presented a value smaller than $0.0095 \mathrm{~m}$. The six-degree-of-freedom displacements of each model were measured using a motion tracking system developed by Qualisys. This system measures the instantaneous position of small targets (with negligible weight) attached to the top of the models using a set of infrared cameras placed in fixed positions. The uncertainty of the motion measurement is evaluated through the relative position of the markers attached to the buoy. This uncertainty is determined though the difference between the average error (residual) of the position of the measured markers when compared with the position of the markers during the definition of the rigid body. The residual depends on the actual motion of the buoy and can change during a test. For these tests, the residual was typically around $0.5 \mathrm{~mm}$, however it reached $4 \mathrm{~mm}$ under extreme motions. The mooring line tension was measured using miniature 'S-beam' (Futek LSB120) load cells attached in series to the lines at the fairlead. The sensor has a range of $\pm 445 \mathrm{~N}$ and nonlinearity of $0.2 \%$. The data from the wave gauges and from the motion tracking system was acquired at a rate of $128 \mathrm{~Hz}$. An acquisition rate of $1667 \mathrm{~Hz}$ was used for the tension measurements.

A view of an array being tested at the wave basin is presented in Fig. 6 . It is possible to observe the targets used by the motion tracking system on the top of the buoys. Several wave gauges are also displayed.

In this paper we analyse results of tests from: $(i)$ moderate irregular-wave sea states; and (ii) extreme irregular-wave sea states (survivability tests). The sea states were based on the wave climate observed off the coast of Leixões, Portugal. The wave conditions were generated with the Njord Wave Synthesis program and were based on a Pierson-Moskowitz (PM) spectrum, characterized by the significant wave height $H_{\mathrm{s}}$ and the energy period $T_{\mathrm{e}}$ [53]. The survivability tests reproduced the 10-, 25-, 50- and 100-year return periods $\left(T_{\mathrm{R}}\right)$ observed in the same location, which were based on the same spectral shape. The sea state wave energy flux increases with its return period, as well as with its peak period $T_{\mathrm{p}}$ (for a PM spectrum, $T_{\mathrm{e}} \approx 0.857 T_{\mathrm{p}}$ ) and significant wave height $H_{\mathrm{s}}$. Due to resonance effects, lower values of peak period can induce higher loads even with smaller significant wave height. Therefore, it was decided to simulate also less energetic sea states. The list of sea states considered for the survivability tests is specified in Table 7 . 
Table 7: List of sea states considered for the simulation of extreme sea conditions (survivability tests). Values refer to full scale.

\begin{tabular}{lrrrr}
\hline Sea state & $T_{\mathrm{R}}[$ years $]$ & $H_{\mathrm{s}}[\mathrm{m}]$ & $T_{\mathrm{p}}[\mathrm{s}]$ & $T_{\mathrm{e}}[\mathrm{s}]$ \\
\hline 1 & 10 & 11.1 & 17.4 & 14.9 \\
2 & 25 & 12.0 & 18.6 & 15.9 \\
3 & 50 & 12.9 & 19.5 & 16.7 \\
4 & 100 & 13.6 & 20.5 & 17.5 \\
\hline
\end{tabular}

Table 8: Natural surge, heave and pitch periods (in seconds) of the isolated device and of the devices in the different array configurations. For the array configurations, a distinction of the natural period from the central and corner devices is made. Values refer to full scale.

\begin{tabular}{lrrrrc} 
& \multicolumn{2}{c}{ Surge } & \multicolumn{2}{c}{ Heave } & Pitch \\
Config. & Central & Corner & Central & Corner & Central \\
\hline Isolated & 102.6 & & 10.0 & & 35.2 \\
Array A & 104.2 & 99.9 & 10.0 & 10.2 & \\
Array B & 146.5 & 139.3 & 9.4 & 9.4 & \\
Array C & 157.1 & 153.4 & 9.3 & 9.2 & \\
Array D & 101.1 & & 9.3 & 9.4 & \\
\hline
\end{tabular}

\section{Results and discussion}

This section presents results obtained from the tests described in Section 3. These tests are divided in the following parts: $(i)$ decay tests; (ii) irregular-wave tests; (iii) survivability tests. The following subsections show the results of the experimental tests and discuss their findings.

\subsection{Decay tests}

Decay tests were carried out to assess the natural periods of the isolated device and of the devices in the array. It is worth noticing that decay tests are performed to analyse oscillatory modes of a dynamic system by introducing an initial displacement of a specific mode. In the case of arrays with inter-body connections, an initial horizontal displacement of a device also introduces displacements in the interconnected devices, which makes the decay tests more difficult to analyse. Due to the symmetry of the mooring lines in the arrays with inter-body connections (B, C, D), surge and sway of the corner devices present the same values. This symmetry is not observed for the independently moored configurations (isolated device and array configuration $\mathrm{A}$ ), as shown in Fig. 2. 
Table 8 presents the full-scale values of the natural surge, heave and pitch period for the isolated device and for the devices in the four array configurations. For the array configurations, a distinction is made between the central and corner devices. The evaluation of the natural surge period allows a better understanding of the stiffness of each mooring system, and therefore helps the system response analysis. The isolated device and the central device of configuration A presents similar natural surge periods. Comparing with the latter, the corner device presents a slightly smaller value. Since the surge stiffness due to the mooring system is proportional to the square root of the natural period, we can observe that configurations $\mathrm{B}$ and $\mathrm{C}$ present smaller stiffness than configuration A. In all cases, the corner and the central devices present similar natural surge periods. For configuration D, it was not possible to determine the natural surge period of the corner device since the tests did not present a clear and stable decay. This issue is believed to be related to the dynamics induced by the surrounding devices.

The natural heave period presents a value around $10.0 \mathrm{~s}$ for the independentlymoored devices (isolated device and array configuration A). For the arrays with inter-body connections, the natural heave period presents smaller values, between 9.2 and $9.4 \mathrm{~s}$. This reduction could be justified by the decrease of the clump weight mass. Pitch decay tests were done only for the isolated device. Natural pitch and roll periods are expected to have very similar natural period values due to the device axisymmetric geometry. The natural pitch period presented a value of $35.2 \mathrm{~s}$, about 3.5 times larger than the natural heave period, and therefore avoiding the condition that promotes parametric resonance in roll and pitch, which induces a dynamic instability [54]. Parametric resonance tends to be triggered when the natural pitch/roll period value is twice the incoming wave period, being more severe for large heave amplitudes. The natural pitch/roll period can be tuned by controlling the metacentric height, which depends on the device geometry and mass distribution. In this case the metacentric height shows a relatively small value $(2.08 \mathrm{~m}$ ) (see Table 1$)$, and therefore small initial stability. Additional information the decays tests can be found in [55].

\subsection{Moderate sea conditions}

Moderate irregular-wave conditions were simulated using a PM spectrum characterized by the significant wave height $\left(H_{\mathrm{s}}\right)$ and energy period $\left(T_{\mathrm{e}}\right)$ [53], as described in Section 3. Fig. 7 shows the root-mean-square values of the oscillation modes of the buoy $\left(\sigma_{x_{i}}\right.$, for $\left.i=1, \ldots, 6\right)$, three translations 

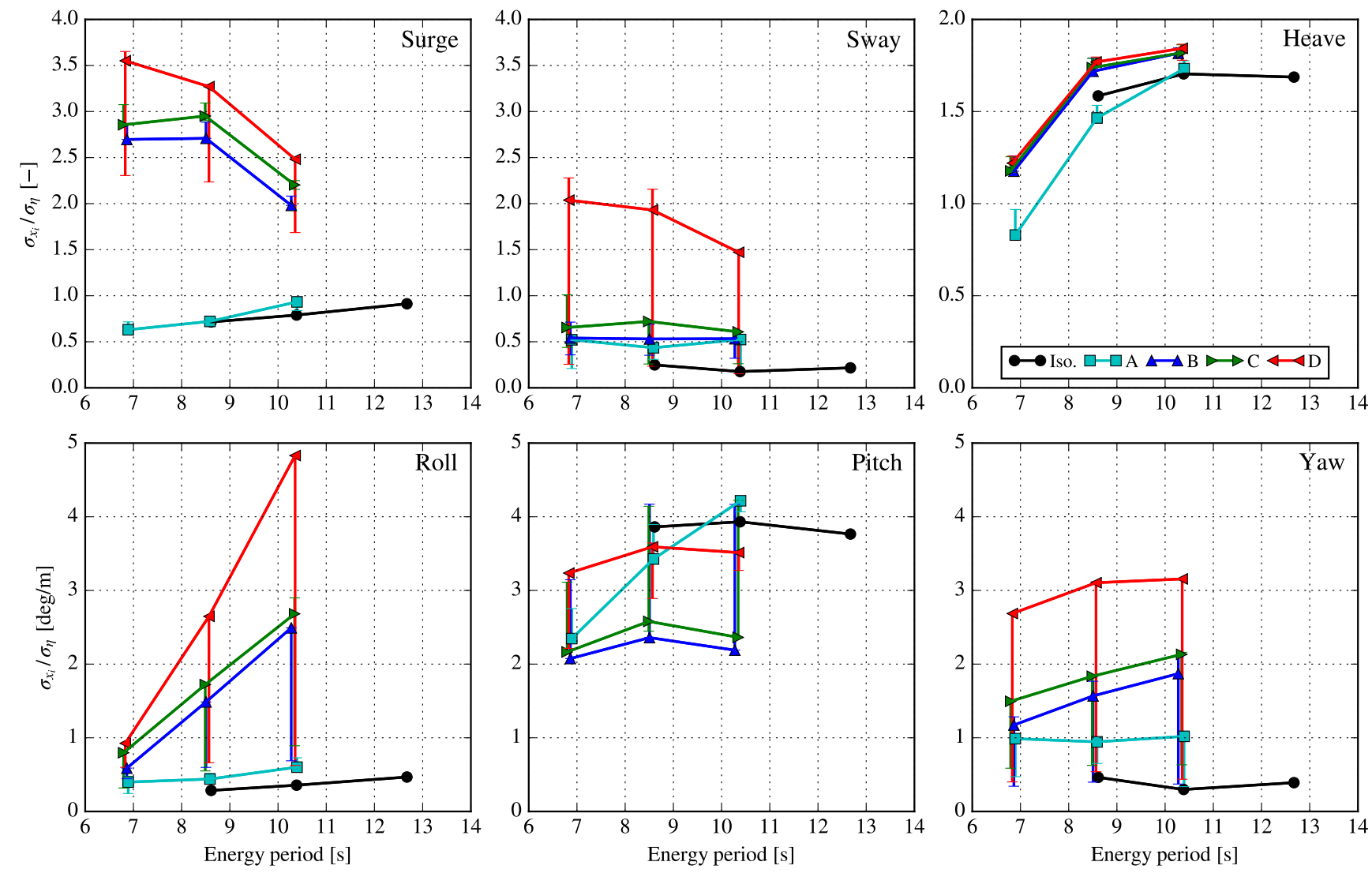

Figure 7: Normalized root-mean-square values of the six-degree-of-freedom displacement for sea states with different energy period $T_{\mathrm{e}}$ and $H_{\mathrm{s}}=2.14 \mathrm{~m}$, for the isolated device and the four array configurations (A, B, C, D). Symbols represent the central device of the array and the vertical bars indicate the minimum and maximum values found within the array.
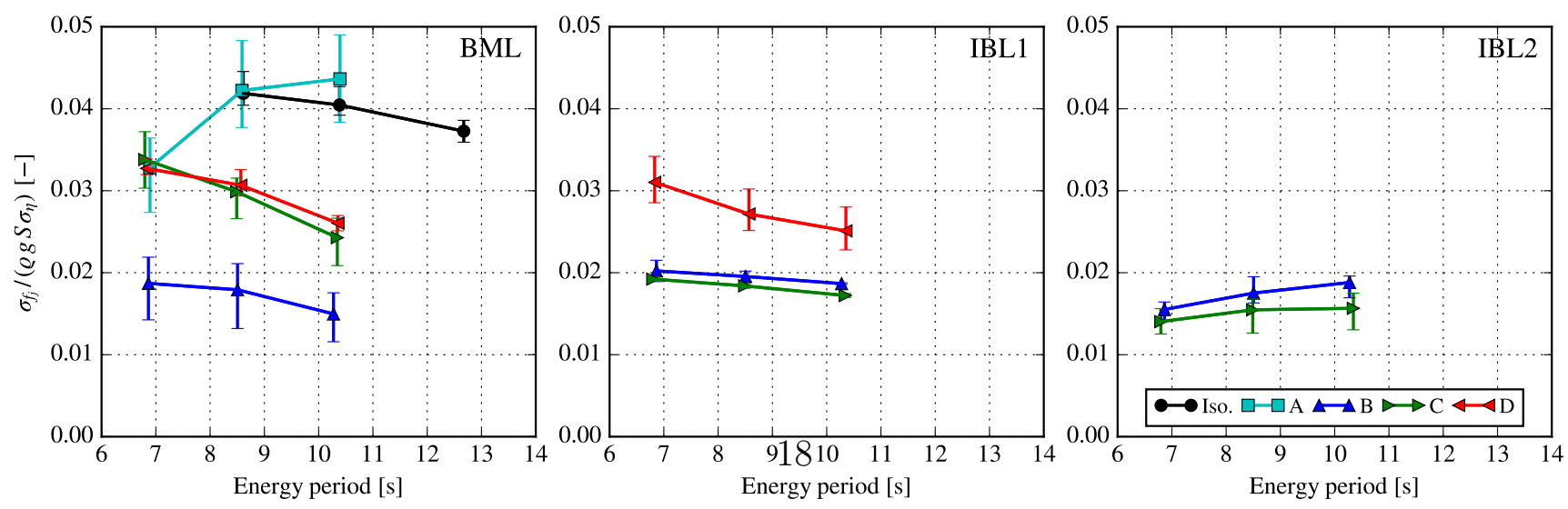

Figure 8: As in Fig. 7, for the dimensionless root-mean-square value of tension in the different types of lines (BML, IBL1, IBL2). 
(surge $x_{1}$, sway $x_{2}$ and heave $x_{3}$ ) and three rotations (roll $x_{4}$, pitch $x_{5}$ and yaw $x_{6}$ ), divided by the root-mean-square values of the free surface elevation generated by the incident wave $\left(\sigma_{\eta}\right)$. The values are presented as a function of the full-scale energy period $T_{\mathrm{e}}$. The symbols refer to values measured in the central device (or in the isolated device), whereas the vertical bars indicate the minimum and the maximum values measured within the array.

Of all the array configurations, A presents the least variations within the devices of the array. This seems to indicate that the complex behaviour of the arrays with inter-body connections induces distinct displacements on the devices, more important than the array effect generated by the wave action. An additional contribution for this effect can also be the difference in line stiffness, which is higher for configuration A, as shown by the natural surge periods from Table 8 . The smallest variations within the array are observed in heave. In this mode, the hydrostatic stiffness is predominant over the mooring system stiffness. Two distinct heave responses are observed, one for the isolated device and configuration $\mathrm{A}$, the other for configurations $\mathrm{B}, \mathrm{C}$ and D. These responses occur due to the relatively larger vertical stiffness introduced by the mooring lines of the isolated device and configuration A, where the clump weight mass is $10 \%$ the value of the buoy mass, which is large enough to affect the heave response relative to the other configurations (see Tables 2, 3, 4 and 5).

The surge response shows larger displacements for inter-body connected arrays. The reduction of connectivity (fewer lines) seems to promote larger surge displacements. A similar trend is also observed for sway, roll and yaw. The large differences observed in surge between the independently-moored array and those with inter-body connections are a consequence of the distinct mooring stiffness.

Fig. 8 presents the dimensionless root-mean-square value of the line tension measured at the device fairlead as a function of the energy period, for a significant wave height of $2.14 \mathrm{~m}$. This parameter is defined as

$$
\sigma_{f_{i}}^{*}=\frac{\sigma_{f_{i}}}{\varrho g S \sigma_{\eta}},
$$

where $\varrho$ is the water density, $g$ is the acceleration of gravity and $S$ is the buoy waterplane area $\left(S=\pi\left(d_{1}^{2}-d_{2}^{2}\right) / 4\right)$. The root-mean-square value of the line tension $j\left(\sigma_{f_{j}}\right)$ is measured relatively to the pre-tension of line $j$ instead of the average value of $f_{j}$, which already accounts for wave drift. The graphs present results of the three types of lines: BML, IBL1, and 
IBL2. The symbols represent the average value and the vertical bars indicate the corresponding maximum and minimum values. Configuration $\mathrm{A}$ and the isolated device present the largest values of mooring line tension. Even though their motions are relatively smaller when compared with those of other array configurations, as shown in Fig. 7, the larger stiffness and pretension values result in higher tensions. Configuration $\mathrm{B}$ presents the smaller overall tensions, considering all types of lines, for the moderate sea states. The reduction of connectivity (fewer lines) in the arrays with inter-body connections have the effect of increasing the line tension variations, a result coherent with the larger displacements observed in Fig. 7.

\subsection{Extreme sea conditions}

In the previous subsection we characterised the device motions and line tension for moderate sea conditions, for the different array configurations. However, under extreme sea conditions, the system nonlinearities are expected to induce a distinct response, as suggested by numerical models [56]. In addition, the maximum line tension is highly relevant to evaluate the system survivability.

The survivability tests simulate a 3-hour full-scale storm condition based on the sea states described in Section 3, whose parameters are indicated in Table 7. Due to the large motion of the devices, green water effects were observed during the experiments. In some cases, water interfered with markers used by the motion tracking system, making the displacement measurement unrealisable.

Fig. 9 shows the root-mean-square values of the six-degree-of-freedom displacements of the buoy normalized by the root-mean-square value of the free surface elevation from the incident wave as a function of the sea state energy period. Unlike in Fig. 7, each point at a given energy period refers to a different significant wave height value, with values ranging from 11.1 to $13.6 \mathrm{~m}$, as indicated in Table 7. As in Fig. 7, the value of the central device is represented by symbols and the vertical bars indicate the maximum and minimum values observed within the array. In the cases where the symbol is absent, the measurement of the displacement was unrealisable. This issue occurred for configurations C and D.

The results present similar trends as in Fig. 7, with significant variations of the displacements of the devices within the array, for the arrays with inter-body connections. These variations increase with the decrease of the connectivity level, with configuration D (least connectivity) showing the 

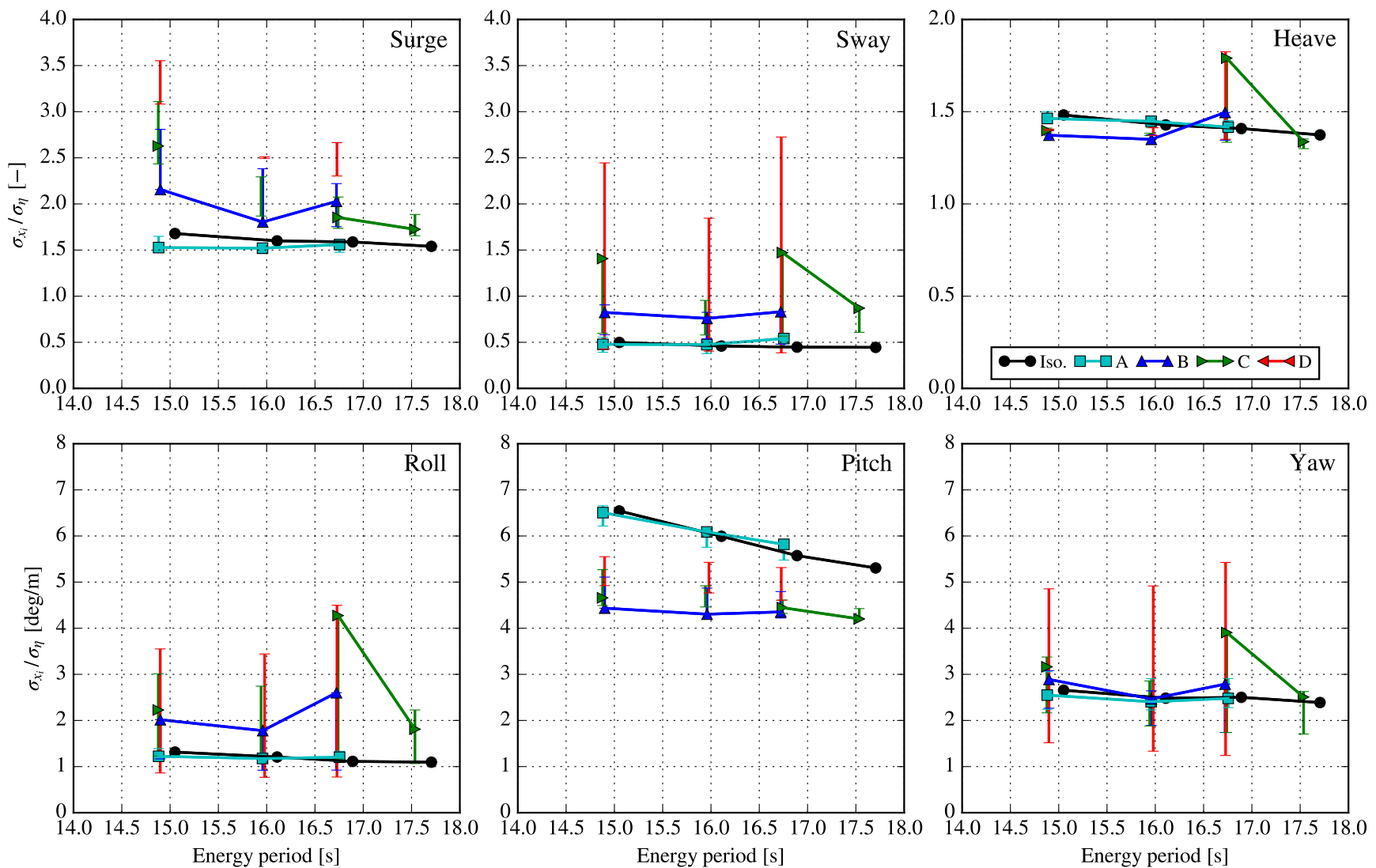

Figure 9: Normalized root-mean-square values of the buoy six-degree-of-freedom displacement for extreme sea states as a function of the energy period $T_{\mathrm{e}}$, for the isolated device and the four array configurations $(\mathrm{A}, \mathrm{B}, \mathrm{C}, \mathrm{D})$. The sea states are based on the PM wave spectrum, with $T_{\mathrm{e}}=14.9,15.9,16.7,17.5 \mathrm{~s}$ and $H_{\mathrm{s}}=11.1,12.0,12.9,13.6 \mathrm{~m}$, respectively. Symbols represent the central device of the array and the vertical bars indicate the minimum and maximum values found within the array.
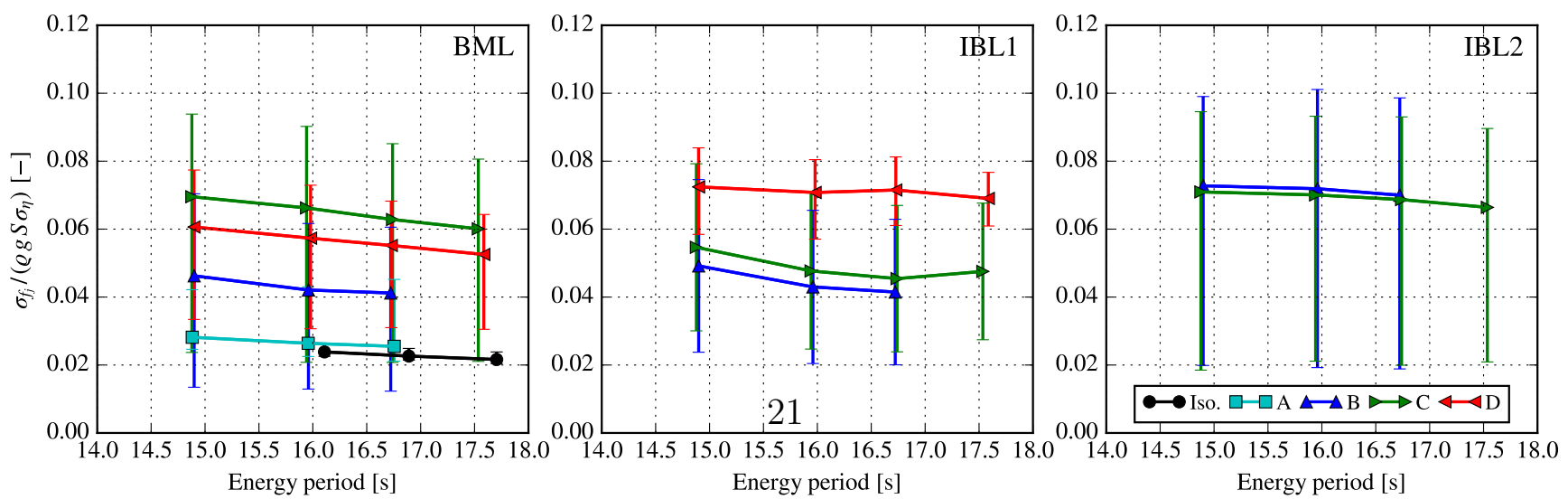

Figure 10: As in Fig. 9, for the dimensionless root-mean-square value of tension in the different types of lines (BML, IBL1, IBL2). Symbols represent the average value from the corresponding type of line and the vertical bars indicate the minimum and maximum values. 

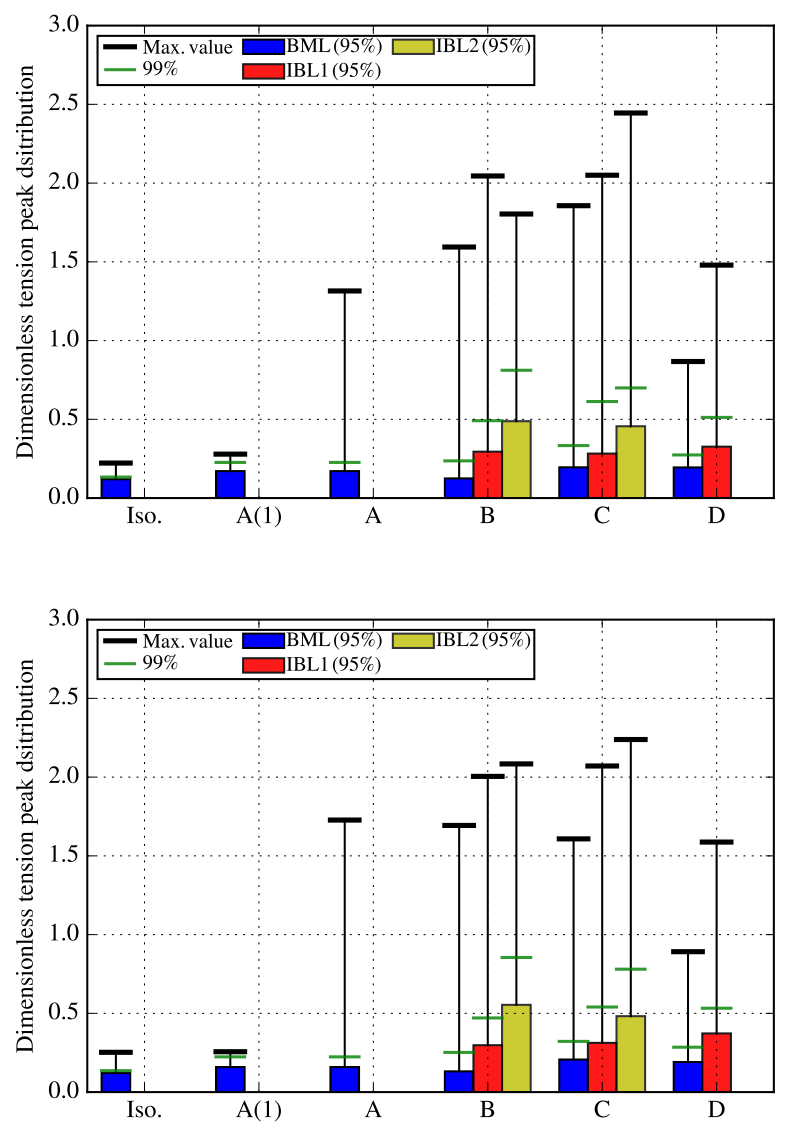

Figure 11: Distribution of dimensionless peak tension for the extreme sea state 2 with $H_{\mathrm{s}}=12.0 \mathrm{~m}$ and $T_{\mathrm{e}}=15.9 \mathrm{~s}$ (top graph), and sea state 3 with $H_{\mathrm{s}}=12.9 \mathrm{~m}$ and $T_{\mathrm{e}}=$ $16.7 \mathrm{~s}$ (bottom graph), for each type of line (BML, IBL1, IBL2) and for all configurations (isolated, A, B, C, D). 

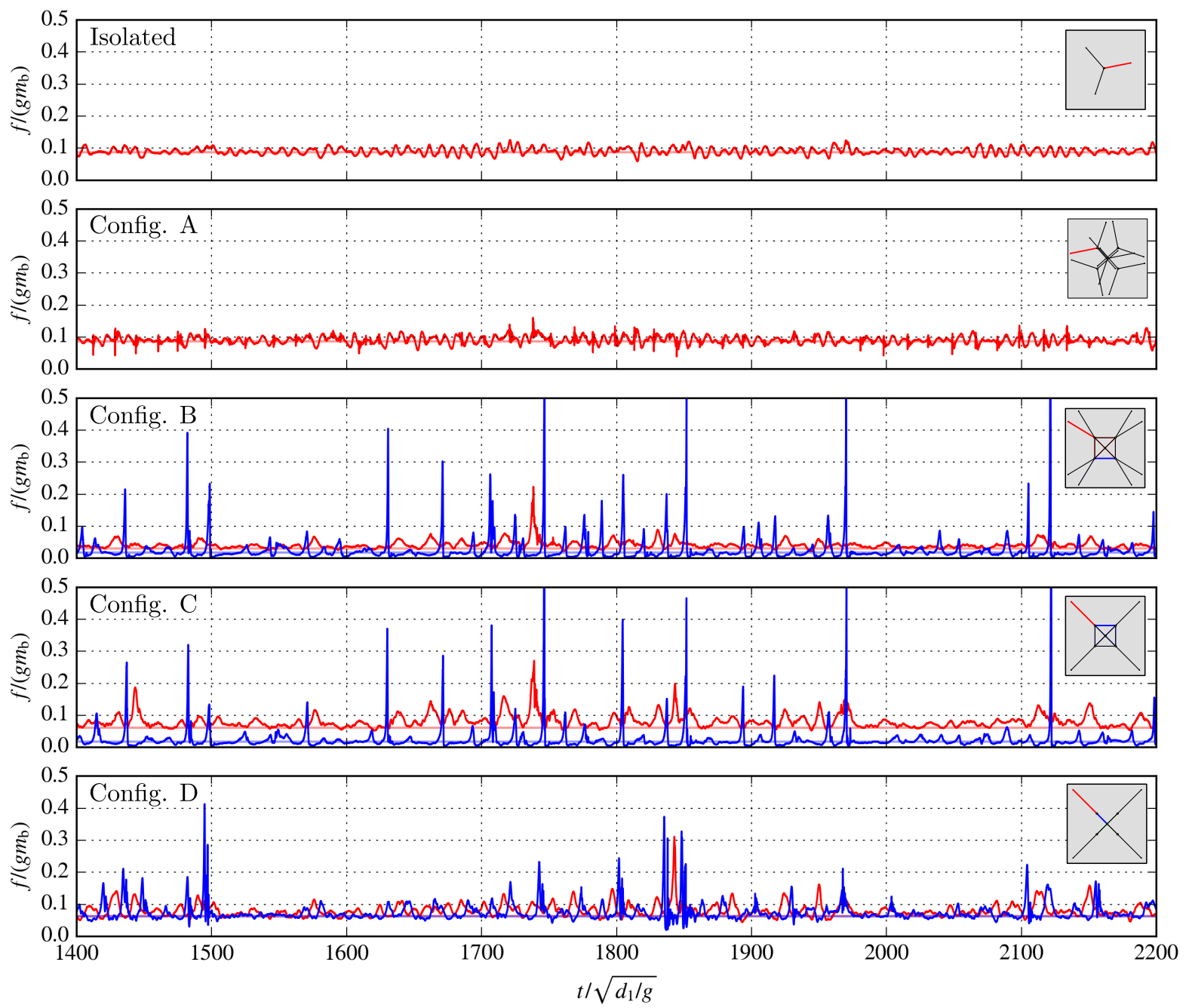

Figure 12: Time series of dimensionless line tension $\left(f /\left(g m_{\mathrm{b}}\right)\right)$ measured during experiments for the isolated device and for all four array configurations. The time variation is presented in its dimensionless format $\left(t / \sqrt{d_{1} / g}\right)$. In all cases, the same wave conditions are considered, corresponding to the extreme sea state 2 (see Table 7 ). The mooring lines corresponding to each time series are identified in the top view. The horizontal lines represent the pre-tension value. 
largest variations. For the most part, configuration A and the isolated device present the smallest displacements, with the exception of heave and pitch.

The dimensionless root-mean-square values of the line tensions from the survivability tests are presented in Fig. 10. The BMLs from the isolated device and from the array configuration A present similar values to the ones found for moderate sea conditions (Fig. 10), which is coherent with the motions not being significantly different. The configurations with inter-body connections (B, C, D) show clearly larger dimensionless tensions than in Fig. 8. The variations of tensions are also significantly larger in the survivability tests. This indicates that highly nonlinear effects are present in these cases. For the configurations with inter-body connections, B shows smaller tensions than the other configurations with less connectivity, with IBL2 being the only exception. The high values observed for the IBL2 are believed to be associated with the line becoming highly stretched during tests, which is related with the relatively small line-length-to-separating-distance ratio $l_{\mathrm{t}} / l_{\mathrm{e}}$ indicated in Table 3. This coefficient measures the relative amount of length that the line is able to stretch.

Fig. 11 presents a more detailed analysis of the loads observed during tests, by plotting values of the dimensionless peak tension $\left(f_{\text {peak }}^{*}\right)$ distribution of the highest tensioned line, for each configuration and for each line type. In addition, the values from the mooring lines of configuration A central device are also shown, which is indicated in the figure as $\mathrm{A}(1)$. This required the determination of each individual peak from the time series. The dimensionless value of the line tension $f$ is defined as

$$
f^{*}=\frac{f}{g m_{\mathrm{b}}} .
$$

Results from sea states 2 and 3 are shown, as these were tested for all configurations. For both sea states, the values and trends are identical. The solid bars display the value of the $95^{\text {th }}$ percentile, which indicates that $95 \%$ of the tension peaks have a value equal or below this tension. Focussing only on these values, we can see that smaller ones are observed for the mooring lines of the isolated device. Relatively higher values are observed for the lines of configuration A, which were measured in a line that has a smaller angle with the incident wave direction and is located in the device waveward side, therefore more subject to the wave drift force. For the arrays with inter-body connections, considering the $95^{\text {th }}$ percentile, the BML presents the least value in all cases, followed by IBL1, and with IBL2 presenting the largest tensions 
(for configurations $\mathrm{B}$ and $\mathrm{C}$ ). The smaller line-length-to-separating-distance ratio $l_{\mathrm{t}} / l_{\mathrm{e}}$ of IBL2 might justify this tendency. Regarding the $99^{\text {th }}$ percentile and maximum values, it can be observed that the maximum peak values are much higher than the corresponding $99^{\text {th }}$ percentile, from 2 to 6 times larger for the array configurations. This indicates that highly abnormal tension values are observed for very few peaks, which are far from representing the whole tension time series. This problem is likely to be mitigated by using lines with a larger length, for both BMLs and IBLs. In general, within an array, lines with the smallest and the largest $95^{\text {th }}$ percentile also show the smallest and the largest maximum values, respectively. The isolated device shows the smaller maximum tensions from all cases considered. By comparing the values from the $95^{\text {th }}$ and $99^{\text {th }}$ percentiles, the mooring lines tension distribution of configuration A central device (denominated as A(1) in Fig. 11) presents very similar values to the one measured considering the whole array. However, the maximum value is much smaller, displaying a value identical to the one found for the isolated device, where the mooring lines had the same orientation. This appears to indicate that the hydrodynamic array effect did not have a relevant impact on these values. Therefore, performing survivability studies on arrays by analysing each device independently appears to be a reasonable assumption, which can allow tests at a larger scale while using the same wave tank.

It is worth mentioning that the array configurations presented here were designed to fit the dimensions of the wave tank. One major consequence was the limitation of the length of the mooring lines. In the case of configuration A, the central device had the same lines as the isolated one. However, the lines of the corner devices had to be rotated to avoid collision with surrounding lines due to the relatively small distance between devices. This constraint implied that some lines on the devices waveward had a small angle with the incident wave (see Fig. 2), being more subject to wave effects (e.g. wave drift force). Comparing the results of the isolated device and configuration A, similar root-mean-square values of displacements and tensions are observed. The major difference was found in the maximum tension, with array configuration A having a much larger tension in a line in the array waveward. This result shows how important is the arrangement of the lines.

The arrays with inter-body connections showed large variability in the device displacement and line tension within the same array. The IBL2 showed the largest maximum tension, a value that might be associated with the small line-length-to-separating-distance ratio $l_{\mathrm{t}} / l_{\mathrm{e}}$, which causes this line to 
become fully stretched under extreme wave action. Likely for this reason, array configuration D, which did not have IBL2, showed the best overall performance, with the smallest maximum tensions.

Fig. 12 shows the time series of mooring line tension measured in the devices fairlead during experiments, for some selected lines of the isolated device and all four array configurations. The time variation is presented in its dimensionless format $\left(t / \sqrt{d_{1} / g}\right)$. The selected lines correspond to cases where the largest tension for a given configuration was measured. All graphs present the response to the same incident wave condition, whose spectrum is characterized by the extreme sea state $2\left(H_{\mathrm{s}}=12.0 \mathrm{~m}\right.$ and $\left.T_{\mathrm{e}}=15.9 \mathrm{~s}\right)$. These are the same conditions as the top graph of Fig. 11. For each line, the pre-tension values are identified. Smaller tension variations are observed for the isolated device and array configuration A. The inter-body connected arrays, in particular the inter-body lines, present clearly larger variations. These variations seem smaller for the array configuration $\mathrm{D}$, where the highest loaded line is IBL 1, instead of IBL 2 as for configurations B and C. The largest peaks, which exceed the maximum value plotted in the graph for IBL 2 in configurations $\mathrm{B}$ and $\mathrm{C}$, are a result of an almost complete extension of the mooring line. The results observed in Fig. 12 agree with the ones from Fig. 11.

As a guidance for future studies on arrays, several considerations can be gathered from this study. A longer scope of the bottom-moored lines is expected to reduce the line tension peaks. In this work, the area used for the deployment of the lines was constrained by the dimensions of the tank, which limited the length of the mooring lines. Due to the small separating distance between devices, the independently-moored array required a mooring configuration different from the isolated device, which resulted in the rotation of the lines attachment points relative to the vertical axis of the device. As a consequence, in some lines, the new orientation, closer to the incident wave direction, resulted in large peak tensions. For independently-moored arrays, using a longer length for critical lines and using distinct mooring arrangement for each device can avoid this problem. For arrays with inter-body connections, the bottom-moored lines should have better performance with more adequate orientations and longer lengths. The inter-body lines should have a relatively large line-length-to-separating-distance ratio to avoid cases where the lines become completely stretched, generating high tension peaks. This can be done by increasing the line angle at the fairlead or through a more complex arrangement with additional clump weights or floats. 


\section{Conclusions}

In this paper we present an experimental study on the dynamic response and mooring tensions of different mooring arrangements of a five-device dietype array of spar-buoy oscillating-water-column devices. Model scale tests were performed at a wave basin for moderate and extreme sea states. We compare the performance of different arrays with inter-body mooring connections, by varying the number of lines used between devices and attached to the seafloor. Moreover, the results of an array with independently-moored devices and an isolated device were used for comparison. The mooring arrangements were specifically designed for these tests. The inter-body connected array with the smallest level of connectivity shows a high potential for cost reduction, as it presents reductions of $58 \%$ in line length and a $73 \%$ in the number of anchors when compared with the independently moored array.

The moderate sea states results show that arrays with inter-body connections present larger motions but smaller line tensions than the independently moored array, which is linked with the smaller pre-tension of the arrays with inter-body connections. The tests for extreme sea conditions presented distinct results, with the arrays with inter-body connections still displaying larger motion, but also presenting a significantly larger line tension, when compared with the independently moored array. The largest tension peaks were observed in the inter-body lines with smaller line-length-to-separatingdistance ratio. Due to some mooring lines being oriented near the wave direction, the independently moored array also presented significant tension peaks yet not as frequent as for the inter-body connected arrays. Overall, the isolated device mooring system, with three bottom-moored lines, displayed

the best performance of all cases. The hydrodynamic interaction between devices showed a negligible impact on the mooring line loads.

For future works, three major guidelines should be considered to reduce line loads. Longer bottom-moored lines should be applied. For the independently moored array, lines should present an adequate orientation. For the inter-body lines, a larger line-length-to-separating-distance ratio should be considered, which may require a more complex line arrangement.

\section{Acknowledgements}

This work was funded by the European Commission's Horizon 2020 program, under the Wave Energy Transition to Future by Evolution of Engineer- 
ing and Technology project (WETFEET), with grant agreement No. 641334. This work was also partially supported by the Portuguese Foundation for Science and Technology (FCT) through IDMEC, under LAETA, project UIDB/50022/2020.

\section{References}

[1] A. F. O. Falcão, Wave energy utilization: A review of the technologies, Renewable \& Sustainable Energy Reviews 14 (3) (2010) 899-918. doi:10.1016/j.rser.2009.11.003.

[2] D. Magagna, R. Monfardini, A. Uihlein, JRC ocean energy status report: 2016 edition, Tech. rep., European Commission's Joint Research Centre (2016). doi:10.2760/509876.

[3] D. Clemente, P. Rosa-Santos, F. Taveira-Pinto, On the potential synergies and applications of wave energy converters: A review, Renewable and Sustainable Energy Reviews 135 (2021) 110162. doi:10.1016/j.rser.2020.110162.

[4] J. Hu, B. Zhou, C. Vogel, P. Liua, R. Willden, K. Sun, J. Zang, J. Geng, P. Jin, L. Cui, B. Jiang, M. Collu, Optimal design and performance analysis of a hybrid system combing a floating wind platform and wave energy converters, Applied Energy 269 (2020) 114998. doi:10.1016/j.apenergy.2020.114998.

[5] H. P. Nguyen, C. M. Wang, Z. Y. Tay, V. H. Luong, Wave energy converter and large floating platform integration: A review, Ocean Engineering 213 (2020) 107768. doi:10.1016/j.oceaneng.2020.107768.

[6] C. Perez-Collazo, S. Astariz, J. Abanades, D. Greaves, G. Iglesias, Co-located wave and offshore wind farms: a preliminary case study of an hybrid array, Coastal Engineering Proceedings 1 (34) (2014). doi:10.9753/icce.v34.structures.33.

[7] A. Babarit, A database of capture width ratio of wave energy converters, Renewable Energy 80 (2015) 610-628. doi:10.1016/j.renene.2015.02.049.

[8] H. Díaz, C. Guedes Soares, Review of the current status, technology and future trends of offshore wind farms, Ocean Engineering 209 (2020) 107381. doi:10.1016/j.oceaneng.2020.107381. 
[9] A. Babarit, On the park effect in arrays of oscillating wave energy converters, Renewable Energy 58 (2013) 68-78. doi:10.1016/j.renene.2013.03.008.

[10] B. Borgarino, A. Babarit, P. Ferrant, Impact of wave interactions effects on energy absorption in large arrays of wave energy converters, Ocean Engineering 41 (2012) 79 - 88. doi:10.1016/j.oceaneng.2011.12.025.

[11] Q. Zhong, R. W. Yeung, Wave-body interactions among energy absorbers in a wave farm, Applied Energy 233-234 (2019) 1051-1064. doi:10.1016/j.apenergy.2018.09.131.

[12] M. Murai, Q.Li, J. Funada, Study on power generation of single point absorber wave energy converters (PA-WECs) and arrays of PA-WECs, Renewable Energy (2020). doi:10.1016/j.renene.2020.08.124.

[13] S. Zou, O. Abdelkhalik, Collective control in arrays of wave energy converters, Renewable Energy 156 (2020) 361-369. doi:10.1016/j.renene.2020.04.069.

[14] A. López-Ruiz, R. J. Bergillos, J. M. Raffo-Caballero, M. OrtegaSánchez, Towards an optimum design of wave energy converter arrays through an integrated approach of life cycle performance and operational capacity, Applied Energy 209 (2018) 20-32. doi:10.1016/j.apenergy.2017.10.062.

[15] L. Martinelli, P. Ruol, G. Cortellazzo, On mooring design of wave energy converters: The seabreath application, in: Coastal Engineering Proceedings, Vol. 1, 2012.

[16] J. B. Thomsen, F. Ferri, J. P. Kofoed, K. Black, Cost optimization of mooring solutions for large floating wave energy converters, Energies 11 (159) (2018) 1-23. doi:10.3390/en10070853.

[17] LCICG, Technology innovation needs assessment (TINA): Marine energy summary report, Tech. rep., Low Carbon Innovation Co-ordination Group, London, UK (2012).

[18] SI Ocean, Ocean energy: Cost of energy and cost reduction opportunities, Tech. rep., Strategic Initiative for Ocean Energy (2013). 
[19] D. W. Fredriksson, J. DeCew, M. Robinson Swift, I. Tsukrov, M. D. Chambers, B. Celikkol, The design and analysis of a four-cage grid mooring for open ocean aquaculture, Aquacultural Engineering 32 (2004) 7794. doi:10.1016/j.aquaeng.2004.05.001.

[20] Z. Gao, T. Moan, Mooring system analysis of multiple wave energy converters in a farm configuration, in: Proceedings of the 8th European Wave Tidal Energy Conference, Uppsala, Sweden, 2009, pp. 509-518.

[21] P. C. Vicente, A. F. de O. Falcão, L. M. C. Gato, P. A. P. Justino, Dynamics of arrays of floating point absorber wave energy converters with inter-body and bottom slack-mooring connections, Applied Ocean Research 31 (2009) 267-281. doi:10.1016/j.apor.2009.09.002.

[22] C. L. G. Oikonomou, R. P. F. Gomes, L. M. C. Gato, A. F. O. Falcão, On the dynamics of an array of spar-buoy oscillating water column devices with inter-body mooring connections, Renewable Energy 148 (2020) 309-325. doi:10.1016/j.renene.2019.11.097.

[23] J. C. C. Portillo, K. M. Collins, R. P. F. Gomes, J. C. C. Henriques, L. M. C. Gato, B. D. Howey, M. R. Hann, D. M. Greaves, A. F. O. Falcão, Wave energy converter physical model design and testing: The case of floating oscillating-water-columns, Applied Energy 278 (2020) 115638. doi:10.1016/j.apenergy.2020.115638.

[24] M. C. Haller, A. Porter, P. Lenee-Bluhm, K. Rhinefrank, E. Hammagren, T. Özkan-Haller, et al., Laboratory observations of waves in the vicinity of WEC-arrays, in: Proceedings of the 9th European Wave Tidal Energy Conference, Southampton, UK, 2011.

[25] S. Yang, H. He, H. Chen, Y. Wang, H. Li, S. Zheng, Experimental study on the performance of a floating array-point-raft wave energy converter under random wave conditions, Renewable Energy 139 (2019) 538-550. doi:10.1016/j.renene.2019.02.093.

[26] V. Krivtsov, B. Linfoot, Basin testing of wave energy converters in Trondheim: Investigation of mooring loads and implications for wider research, Journal of Marine Science and Engineering 2 (2014). doi:10.3390/jmse2020326. 
[27] J.-R. Nader, A. Fleming, G. Macfarlane, I. Penesis, R. Manasseh, Novel experimental modelling of the hydrodynamic interactions of arrays of wave energy converters, International Journal of Marine Energy 20 (2017) 109-124. doi:10.1016/j.ijome.2017.11.003.

[28] V. Stratigaki, P. Troch, T. Stallard, D. Forehand, J. P. Kofoed, M. Folley, et al., Wave basin experiments with large wave energy converter arrays to study interactions between the converters and effects on other users in the sea and the coastal area, Energies 7 (2) (2014) 701-734. doi:10.3390/en7020701.

[29] F. X. Correia da Fonseca, R. P. F. Gomes, J. C. C. Henriques, L. M. C. Gato, A. F. O. Falcão, Model testing of an oscillating water column sparbuoy wave energy converter isolated and in array: Motions and mooring forces, Energy 112 (2016) 1207-1218. doi:10.1016/j.energy.2016.07.007.

[30] Position mooring, DNV Offshore Standard DNV-OS-E301 (2013).

[31] Petroleum and natural gas industries - Specific requirements for offshore structures - Part 7: Stationkeeping systems for floating offshore structures and mobile offshore units. ISO 19901-7 (2005).

[32] Guidelines on design and operation of wave energy converters, Det Norske Veritas (Carbon Trust Guidelines) (2005).

[33] P. C. Vicente, A. F. O. Falcão, P. A. P. Justino, Slack-chain mooring configuration analysis of a floating wave energy converter, in: Proceedings of the 26th International Workshop on Water Waves and Floating Bodies, Athens, Greece, 2011.

[34] G. M. Paredes, J. Palm, C. Eskilsson, L. Bergdahl, F. Taveira-Pinto, Experimental investigation of mooring configurations for wave energy converters, International Journal of Marine Energy 15 (2016) 56-67. doi:10.1016/j.ijome.2016.04.009.

[35] R. P. F. Gomes, J. C. C. Henriques, L. M. C. Gato, A. F. O. Falcão, Time-domain simulation of a slack-moored floating oscillating water column and validation with physical model tests, Renewable Energy 149 (2020) 165-180. doi:10.1016/j.renene.2019.11.159. 
[36] G. Giorgi, R. P. F. Gomes, J. C. C. Henriques, L. M. C. Gato, G. Bracco, G. Mattiazzo, Detecting parametric resonance in a floating oscillating water column device for wave energy conversion: Numerical simulations and validation with physical model tests, Applied Energy 276 (2020) 115421. doi:10.1016/j.apenergy.2020.115421.

[37] R. G. Coe, Y.-H. Yu, J. van Rij, A survey of WEC reliability, survival and design practices, Energies 11 (4) (2018) 1-19. doi:10.3390/en11010004.

[38] E. Ransley, D. Greaves, A. Raby, D. Simmonds, M. Hann, Survivability of wave energy converters using CFD, Renewable Energy 109 (2017) 235-247. doi:10.1016/j.renene.2017.03.003.

[39] J. Davidson, J. V. Ringwood, Mathematical modelling of mooring systems for wave energy converters - a review, Energies 10 (5) (2017) 666. doi:10.3390/en10050666.

[40] J. B. Thomsen, F. Ferri, J. P. Kofoed, Screening of available tools for dynamic mooring analysis of wave energy converters, Energies 10 (853) (2017) 1-18. doi:10.3390/en10070853.

[41] M. Hann, D. Greaves, A. Raby, Snatch loading of a single taut moored floating wave energy converter due to focussed wave groups, Ocean Engineering 96 (2015) 258-271. doi:10.1016/j.oceaneng.2014.11.011.

[42] M. Hann, D. Greaves, A. Raby, B. Howey, Use of constrained focused waves to measure extreme loading of a taut moored floating wave energy converter, Ocean Engineering 148 (2018) 33-42. doi:10.1016/j.oceaneng.2017.10.024.

[43] V. Heller, Ocean energy: Development of wave devices from initial conception to commercial demonstration, in: A. A. Sayigh (Ed.), Comprehensive Renewable Energy, Vol. 8, Elsevier, 2012, Ch. 4, pp. 79-110. doi:10.1016/B978-0-08-087872-0.00804-0.

[44] L. Johanning, G. H. Smith, J. Wolfram, Measurements of static and dynamic mooring line damping and their importance for floating WEC devices, Ocean Engineering 34 (2007) 1918-1934. doi:10.1016/j.oceaneng.2007.04.002. 
[45] V. Harnois, S. D. Weller, L. Johanning, P. R. Thies, M. Le Boulluec, D. L. Roux, et al., Numerical model validation for mooring systems: Method and application for wave energy converters, Renewable Energy 75 (2015) 869-887. doi:10.1016/j.renene.2014.10.063.

[46] A. F. O. Falcão, J. C. C. Henriques, Oscillating-water-column wave energy converters and air turbines: A review, Renewable Energy 85 (2016) 1391-1424. doi:10.1016/j.renene.2015.07.086.

[47] R. P. F. Gomes, J. C. C. Henriques, L. M. C. Gato, A. F. O. Falcão, Hydrodynamic optimization of an axisymmetric floating oscillating water column for wave energy conversion, Renewable Energy 44 (2012) 328 339. doi:10.1016/j.renene.2012.01.105.

[48] B. Teillant, K. Krügel, M. Guérinel, M. Vicente, Y. Debruyne, F. Malerba, et al., Wave Energy Transition to Future by Evolution of Engineering and Technology (WETFEET) project. Deliverable 2.3: Engineering challenges related to full scale and large deployment implementation of the proposed breakthroughs, Tech. rep., European Union's Horizon 2020 research and innovation programme under grant agreement No 641334 (2016).

[49] M. J. D. Powell, A direct search optimization method that models the objective and constraint functions by linear interpolation, in: S. Gomez, J.-P. Hennart (Eds.), Advances in Optimization and Numerical Analysis, Kluwer Academic, Dordrecht, 1994, pp. 51-67.

[50] M. J. D. Powell, Direct search algorithms for optimization calculations, Acta Numerica 7 (1998) 287-336. doi:10.1017/S0962492900002841.

[51] S. A. Hughes, Physical models and laboratory techniques in coastal engineering, Vol. 7 of Advanced Series on Ocean Engineering, World Scientific Publishing, 1993.

[52] R. P. F. Gomes, J. C. C. Henriques, L. M. C. Gato, A. F. O. Falcão, Experimental tests of a 1:16th-scale model of the spar-buoy OWC in a large scale wave flume in regular waves, in: Proceedings of the ASME 2018 37th International Conference on Ocean, Offshore and Arctic Engineering (OMAE2018), Madrid, Spain, 2018. 
[53] Y. Goda, Random Seas and Design of Maritime Structures, 3rd Edition, World Scientific, Singapore, 2010.

[54] G. Giorgi, R. P. F. Gomes, G. Bracco, G. Mattiazzo, Numerical investigation of parametric resonance due to hydrodynamic coupling in a realistic wave energy converter, Nonlinear Dynamics 101 (2020) 153-170. doi:10.1007/s11071-020-05739-8.

[55] K. Collins, B. Howey, D. Greaves, M. Hann, G. Iglesias, R. P. F. Gomes, et al., Wave Energy Transition to Future by Evolution of Engineering and Technology (WETFEET) project. Deliverable 6.5: Design guidance on the use of shared moorings in compact arrays, Tech. rep., European Union's Horizon 2020 research and innovation programme under grant agreement No 641334 (2018).

[56] G. Giorgi, R. P. F. Gomes, G. Bracco, G. Mattiazzo, The effect of mooring line parameters in inducing parametric resonance on the sparbuoy oscillating water column wave energy converter, Journal of Marine Science and Engineering 8 (1) (2020) 19. doi:10.3390/jmse8010029. 